CONF- $9603137--1$

UCRL-JC-123264

PREPRINT

\title{
Autoignition Chemistry in a Motored Engine: An Experimental and Kinetic Modeling Study
}

\author{
H.J. Curran, W.J. Pitz and C.K. Westbrook \\ Lawrence Livermore National Laboratory
}

P.O. Box 808

Livermore, California 94551

Paolo Gaffuri

Chemical Engineering Department

Politecnico Milano,

Milan, Italy

W.R. Leppard

General Motors Research Laboratories

Warren, MI 74090
RECEIVED

MAR 181996

OSTI

This paper was prepared for submittal to the

Western States Section Meeting

Tempe, $A Z$

March 11-12, 1996

February 1996

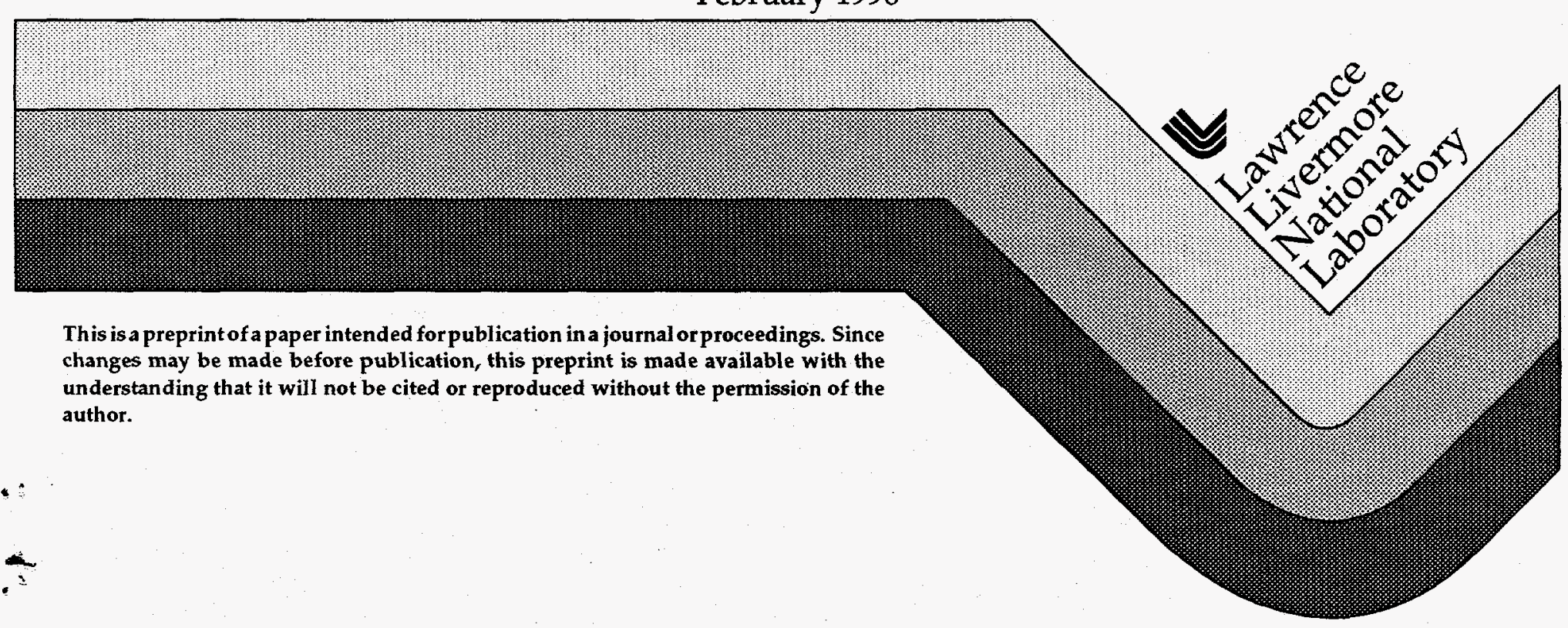




\section{DISCLAIMER}

This document was prepared as an account of work sponsored by an agency of the United States Government. Neither the United States Government nor the University of California nor any of their employees, makes any warranty, express or implied, or assumes any legal liability or responsibility for the accuracy, completeness, or usefulness of any information, apparatus, product, or process disclosed, or represents that its use would not infringe privately owned rights. Reference herein to any specific commercial product, process, or service by trade name, trademark, manufacturer, or otherwise, does not necessarily constitute or imply its endorsement, recommendation, or favoring by the United States Government or the University of California. The views and opinions of authors expressed herein do not necessarily state or reflect those of the United States Government or the University of California, and shall not be used for advertising or product endorsement purposes. 
Autoignition Chemistry in a Motored Engine:

An Experimental and Kinetic Modeling Study

Henry J. Curran, Paolo Gaffuri*, William J. Pitz, Charles K. Westbrook

Lawrence Livermore National Laboratory, Livermore, CA 94550

and

William R. Leppard

General Motors Research Laboratories, Warren, MI 47090

\begin{abstract}
Autoignition of isomers of pentane, hexane, and primary reference fuel mixtures of $n$-heptane and iso-octane has been studied experimentally under motored engine conditions and computationally using a detailed chemical kinetic reaction mechanism. Computed and experimental results are compared and used to help understand the chemical factors leading to engine knock in spark-ignited engines. The kinetic model reproduces observed variations in critical compression ratio with fuel molecular size and structure, provides intermediate product species concentrations in good agreement with observations, and gives insights into the kinetic origins of fuel octane sensitivity. Sequential computed engine cycles were found to lead to stable, non-igniting behavior for conditions below a critical compression ratio; to unstable, oscillating but nonigniting behavior in a transition region; and eventually to ignition as the compression ratio is steadily increased. This transition is related to conditions where a negative temperature coefficient of reaction exists, which has a significant influence on octane number and fuel octane sensitivity.
\end{abstract}

* Current address: Chemical Engineering Dept., Politecnico Milano, Milan, Italy. 


\section{INTRODUCTION}

Engine knock provides a practical limit to the efficiency of spark-ignition engines. Although a great deal of empirical knowledge exists concerning knock tendencies of hydrocarbon fuels, fundamentally based methods of predicting knock tendencies of arbitrary fuel mixtures provide a valuable tool in engine and fuel design.

Hydrocarbon fuel molecular size and structure play significant roles in determining knock tendency and octane rating in spark-ignition engines [1]. Recent studies [2-13] have contributed to a greatly improved understanding of the chemical factors that influence engine knock. These studies indicate that distinctions between different carbon-hydrogen bonds and variations in ring strain energy, especially affecting rates of alkylperoxy radical isomerization reactions, are particularly important.

Isomers of pentane, hexane, heptane and octane represent an interesting family of fuels for the study of knock chemistry. In particular, n-heptane and iso-octane (2,2,4trimethyl pentane) are the primary reference fuels (PRF) that determine the octane rating of automotive fuels. These fuels follow the general pattern for alkane fuels, with octane number increasing with the degree of branching and decreasing with the overall size of the molecule. The Research Octane Number (RON) of the fuels studied here range from $\mathrm{RON}=0$ for $\mathrm{n}$-heptane to $\mathrm{RON}=104$ for 2,3-dimethyl butane and are summarized in Table I. Although other combustion properties of these fuels are quite similar, including adiabatic flame temperature and laminar burning velocity, it is evident that the variability in octane number and knock tendency is due to the molecular size and structure of these isomers.

The five hexane isomers, one pentane isomer and a selected number of PRF mixtures were studied experimentally, employing motored engine techniques. Kinetic modeling analysis was applied to interpret the experimental results. In addition, the model was used to predict conditions for autoignition of the remaining isomers of pentane and other PRF mixtures as a test of its predictive capabilities. 
Previous modeling studies have developed a picture of paraffinic hydrocarbon kinetics under engine conditions. This approach was used [10] to show how pro-knock and anti-knock additives such as tetra-ethyl lead (TEL) and methyl-tert-butyl ether (MTBE) alter fuel autoignition chemistry and change knock tendencies of hydrocarbon fuels. However, previous model studies were tested only against octane rating data, which are integrated quantities and cannot provide detailed tests of the reaction mechanisms. Our recent work [11] studied autoignition of hexane isomers under motored conditions, providing the first species-specific concentration comparisons between model calculations and engine measurements. Mechanism modifications described below were made that improved its abilities to interpret knock behavior.

\section{EXPERIMENTAL STUDIES}

A Waukesha Cooperative Fuels Research (CFR) engine was operated under motored conditions, with stoichiometric fuel-air mixtures at an engine speed of 600 $\mathrm{rpm}$, intake temperature of $403 \mathrm{~K}$, and an intake manifold absolute pressure of $80 \mathrm{kPa}$. A limited number of additional experiments were carried out for iso-octane and other fuels at 500 and $900 \mathrm{rpm}$. The extent of autoignition chemistry was controlled by varying the compression ratio (CR), holding the intake manifold temperature and pressure constant. The engine $C R$ was increased to a critical value where autoignition was observed. This critical $C R$ value was found to vary from one fuel to another and depended strongly on fuel molecular size and structure. For each fuel, chemical species concentrations for a large number of species were measured in the cool exhaust stream under steady operation.

Intake fuel/air composition was monitored with a modified Beckman Model 109A Flame Ionization Detector (FID) in the intake system just upstream from the intake valve. These measurements were periodically confirmed by firing the engine, determining the equivalence ratio with standard exhaust-gas analysis. 
A typical motored engine run involved stabilizing the intake temperature and pressure while motoring the engine on air at the desired speed and a very low $C R$. After stabilization, the ignition was turned on and fuel admitted. The fuel rate was adjusted to achieve an equivalence ratio of 1.0 as measured simultaneously by the intake charge FID and exhaust gas analyzers. The engine was fired for approximately ten minutes to assure stable fuel delivery and to burn any accumulated lubricating oil from the combustion chamber. The ignition was then turned off and the compression ratio adjusted to the desired setting. After stable operation was achieved, the carbon monoxide and oxygen exhaust concentrations were recorded and exhaust gas samples acquired. Carbon monoxide exhaust concentration is a good indicator of the extent of autoignition chemistry occurring for all fuels examined to date.

\section{Analytical Equipment}

Carbon monoxide was measured continuously using a Horiba Model AIA-23 Infrared Analyzer. Oxygen concentration in the exhaust was continuously measured using a Horiba Model MPA-21 Oxygen Analyzer. Both instruments were calibrated prior to each measurement with certified gaseous calibration standards. Exhaust sampling and analyses of other stable intermediate species were performed as described in previous publications [14-16] using gas chromatography for most species and the DNPH derivatization technique of Lipari and Swarin [17] for aldehydes and ketones.

Exhaust gas samples for GC analysis were obtained either with heated, gas-tight syringes or with the gas sampling system described in [14]. These samples were analyzed using the two-dimensional gas chromatographic technique described in $[14,18]$. Unknown intermediate species were identified by a combination of gas chromatographic-mass spectrometry (GC-MS) and gas chromatography-Fourier transform infrared spectroscopy (GC-FTIR). The samples for the GC-MS and GC-FTIR analyses were liquid and were obtained by pulling a fraction of the exhaust through a 
condensation trap immersed in a dry ice-isopropanol bath. Liquid samples were used in preference to gaseous ones as the concentrations of the unknowns were higher providing better responses to both analytical techniques.

\section{Experimental Results}

Measured exhaust concentrations of carbon monoxide are shown as functions of compression ratio for the hexane isomers in the bottom half of Fig. 1 and the experimental PRF mixtures in Fig. 2. Below some CR, there is virtually no reaction; as the $\mathrm{CR}$ increases, the $\mathrm{CO}$ concentration and extent of reaction increase until, at some critical value, autoignition is observed, all without spark ignition in the combustion chamber. For each case, autoignition was observed at a CR slightly greater than the highest value for which a $\mathrm{CO}$ concentration is shown in Figs. 1 and 2. The experimental variation in critical $C R$ is correlated with research octane number (RON) as summarized in Table I. Note however, that this correlation is not especially precise; the two fuels with $R O N=25$ were measured to have critical $C R$ values of 6.4 and 6.8 , while the two fuels with $\mathrm{RON}=75$ had critical $C R$ values of 8.4 and 9.1. This variability reflects the fact that although the present measurements were carried out in a real engine at the same engine speed as that used to determine RON, the operating conditions (i.e., motored here vs. fired in RON tests) are still not entirely the same. Differences in critical CR in Table I show how sensitive RON and critical CR measurements can be to operating conditions. The measured values for critical $\mathrm{CR}$ are shown as filled symbols in Figure 3, illustrating how critical $C R$ is insensitive to $R O N$ for values of RON less than about 60 , but more sensitive for higher RON values.

Chemical species concentrations were measured in the exhaust gases at each $C R$ value as described above. Of particular interest are the results measured at the highest compression ratio that did not produce autoignition and therefore represent the greatest degree of fuel consumption without complete conversion to final products. Results are 
shown for 2-methyl pentane at $600 \mathrm{rpm}$ and iso-octane at $500 \mathrm{rpm}$ in Table II. Comparable results for the other hexane isomers can be found in Ref. [11], while results for the other PRF mixtures are qualitatively similar to those in Table II. In each case, the major products are carbon monoxide, formaldehyde, ethene and other species common to all of these fuels. In addition, each fuel produces a wide variety of larger olefins and oxygenated hydrocarbon species, whose identities and concentrations depend on the fuel being studied. We will discuss these species-specific concentration results below.

\section{COMPUTATIONAL MODEL}

Modeling computations were carried out using the HCT code [19], which has been used in past studies of engine knock and autoignition [10-13]. The engine is treated as a homogeneous reactor, ignoring spatial variations in temperature and species concentrations. Our experience has indicated that these model limitations do not have a serious impact on the value of the simulations, except for some near-limit phenomena as discussed below.

The effects of piston motion, heat losses to the engine chamber walls, blowby, fuel trapping in crevice volumes, and other processes were included by specifying the combustion chamber volume history using a slider-crank formula described by Heywood [20], and by calibrating the distributed heat loss submodel by simulating nonreactive experiments. Simulations of non-reactive mixtures at different compression ratios showed that the overall rate of wall heat transfer increases slightly with increasing $C R$, consistent with increasing surface-to-volume ratio at higher $C R$. Further details can be found in Ref. [11].

It was essential to include the effects of residual gas composition on successive engine cycles. Unlike fired cycles where residual gases are $\mathrm{CO}_{2}, \mathrm{H}_{2} \mathrm{O}$ and $\mathrm{N}_{2}$, under motored conditions the residual gas fraction has a very complex composition. These partially reacted species influence the overall gas mixture reactivity in the combustion 
chamber, as discussed by Green et al. [21]. At each compression ratio, experimental engine data provide the initial gas temperature, residual gas fraction, and initial pressure for the simulation. As reaction time increases, the slider-crank formula and heat transfer rate account for all of the relevant processes except chemical reaction, which is computed explicitly in the kinetics portion of the model.

\section{REACTION MECHANISM}

The detailed chemical kinetic reaction mechanism was based on that used in our previous knock modeling studies [10-13]. Details of the reaction mechanisms are described in Ref. [11], and only a brief summary of the most important features will be presented here. However, a major recent improvement has been a thorough update of the thermochemical variables for many of the chemical species in the model, using the bond additivity rules of Benson [22] as implemented by Ritter and Bozzelli with updated $\mathrm{H} / \mathrm{C} / \mathrm{O}$ and bond dissociation groups $[23,24]$.

Effectively all fuel consumption occurs by $\mathrm{H}$ atom abstraction reactions with $\mathrm{OH}$, $\mathrm{HO}_{2}, \mathrm{H}, \mathrm{O}, \mathrm{CH}_{3}$, and other radical species. Distinctions are made between the abstraction of $\mathrm{H}$ atoms from primary, secondary, and tertiary sites in the fuel molecule $[10,12]$. Although $\beta$-scission of alkyl radicals $R$ is included in the mechanism, under the present conditions most alkyl radicals react via addition of $\mathrm{O}_{2}$ to produce $\mathrm{RO}_{2}$.

Internal $\mathrm{H}$ atom transfer within the $\mathrm{RO}_{2}$ species to produce a $\mathrm{QOOH}$ product is responsible for much of the variability of knock tendency with fuel size and structure

[10-13]. The rates of these reactions depend on the type of $\mathrm{C}-\mathrm{H}$ bond being broken and the size of the intermediate transition state ring involved. Activation energies for these reactions have been updated, and the $A$ factors have been revised to account for the entropy changes involved as the transition state ring increases in size.

These $\mathrm{QOOH}$ species can follow any of four different reaction paths in addition to reverse isomerization back to $\mathrm{RO}_{2}$. These reactions include (1) addition of another 
$\mathrm{O}_{2}$ species to produce $\mathrm{O}_{2} \mathrm{QOOH}$, (2) O-O bond scission followed by the formation of cyclic ether products, and two reaction paths that are possible only for certain types of $\mathrm{QOOH}$ radicals. Except for the addition of the second $\mathrm{O}_{2}$ to $\mathrm{QOOH}$, all of these reaction sequences produce a single $\mathrm{OH}$ or $\mathrm{HO}_{2}$ radical and are effectively chain propagation paths.

In our previous models, decomposition of $\mathrm{O}_{2} \mathrm{QOOH}$ species was treated in an approximate fashion. For the present mechanism, we have improved the treatment of these reactions based on recent studies [25-31]. It is now assumed that an $\mathrm{O}-\mathrm{O}$ bond is broken, producing $\mathrm{OH}$ radicals and a relatively stable ketohydroperoxide species. It is the subsequent decomposition of the ketohydroperoxide that ultimately produces the additional radical species to provide chain branching from this reaction sequence. Since production of ketohydroperoxide provides only one $\mathrm{OH}$ radical, chain branching is delayed until the ketohydroperoxide decomposes, resulting in an induction time in many of the computed results, a phenomenon not available in the previous mechanism and which has been found to be important in some of these simulations [11].

\section{COMPUTED RESULTS}

Engine simulations were carried out for each stoichiometric fuel/air mixture, beginning at the time of intake valve closing at 151.8 degrees before top dead center (TDC), with an engine speed of 600 or $500 \mathrm{rpm}$. For the first engine cycle the fuel/air mixture consisted entirely of unreacted fuel and air; on subsequent cycles the starting mixture consisted of unreacted fuel/air and a fraction of the residual products of the previous cycle, determined from the $C R$. Enough cycles were computed until the products of a given cycle were essentially identical to those of the previous cycle, with occasional exceptions as noted below. For example, concentrations of several species at the end of each of 6 motored cycles at a CR of 12.0 using 95 PRF are shown in Table III. When the species concentrations converged as illustrated here, the series of cycles was 
terminated and a new sequence begun at an increased $C R$. Eventually a critical $C R$ was reached where autoignition was observed. Usually this autoignition was predicted to occur not on the first cycle but after several cycles during which concentrations of intermediate species were seen to increase steadily from one cycle to the next. This behavior is illustrated in Table III for n-hexane at a CR of 5.75.

At still higher $C R$ values, autoignition continued to be observed in the computed results, defining a critical value for the $C R$. These predicted critical compression ratios are compared with experimental results in Table I. The general trends are reproduced well by the model; the ranking of the different fuels is correctly predicted in most cases, and the specific numerical values for each fuel are quite close to the observed values.

Computed values of the critical CR are summarized as open symbols in Fig. 3. The overall agreement between computed results and experimental measurements follows the experimental curve quite closely. Recall that no experiments were run with two of the three pentane isomers, so the model calculations represent predictions; the degree of agreement for these fuels is also good. The computed critical $C R$ values for the PRF mixtures between PRF50 and PRF75 show the most significant difference from the curve representing the measured results, although computed results for higher and lower PRF mixtures agree well with the measurements. Closer examination of the computed results for these PRF mixtures show that negative temperature coefficient (NTC) phenomena are playing a significant role in the oxidation of these mixtures. This point will be discussed in detail in the next section, but it appears that these discrepancies are due to the interaction between the NTC kinetic behavior and the model assumption that the engine can be approximated as a spatially homogeneous reactor, which may be inaccurate under these conditions. 


\section{Fuel Octane Sensitivity}

The computed results show interesting features not observed in the experiments. For 2-methyl pentane, 3-methyl pentane, 2,2-dimethyl butane, and all of the PRF mixtures with RON greater than 50, at compression ratios substantially lower than the critical value, sequential non-igniting cycles demonstrated an oscillatory behavior, with high values on one cycle and low values on the next cycle as illustrated for the 75 PRF mixture in Table III.

For some of these fuels that exhibited oscillatory behavior, as the $C R$ was increased further, autoignition was predicted, generally at a $\mathrm{CR}$ of about 7.5, much lower than the experimentally observed critical $C R$. However, as the $C R$ was increased even further, autoignition ceased and did not recur until the critical value indicated in Table I. For example, autoignition was predicted for 2-methyl pentane at compression ratios of $7.25,7.5$ and 7.75 , while at $C R$ of 8.0 through 8.75 no autoignition was predicted. Similarly, in the case of 3-methyl pentane, autoignition was predicted at a $\mathrm{CR}$ of 7.75, while no ignition was predicted at lower compression ratios or at higher values until the critical value of 8.75 was exceeded.

Closer examination of the kinetic behavior in these models shows that these fuel/air mixtures are passing through a region of negative temperature coefficient (NTC). At compression ratios close to the $7.25-7.75$ range, these reactive mixtures reach temperatures where the overall rate of reaction reaches a temporary maximum, resulting in autoignition. Then, as CR increases further, temperatures near TDC pass into this NTC region, and the rate of reaction decreases, resulting in non-igniting behavior. Finally, at higher compression ratios the overall rate of reaction reaches the same level as that computed at a CR of 7.75 and ignition is again predicted.

The present experiments did not observe this intermediate ignition region. However, for 2-methyl pentane sporadic ignition was observed experimentally at a CR of 8.0, indicating that not every cycle ignited. Recently, Li et al. [32] used a slightly 
different motored technique with fuels including a PRF mixture with $R O N=87$. Li et al. held the inlet pressure fixed at $108.2 \mathrm{kPa}$, increasing the inlet temperature until autoignition began to occur at an inlet temperature of $377 \mathrm{~K}$. As temperature was increased further, autoignition continued until the temperature reached $480 \mathrm{~K}$ where autoignition ceased. Autoignition did not reoccur until the inlet temperature reached $500 \mathrm{~K}$, paralleling the NTC behavior described here.

Additional evidence of NTC behavior is provided by earlier motored engine experiments by Leppard [14-16] under conditions including different engine speeds, a range of intake manifold temperatures and pressures, and a variety of paraffin, olefin and aromatic fuels. Leppard examined the problem of fuel octane sensitivity, which concerns differences in chemical reactivity under Research and Motored conditions. Alkane fuels are characterized by low octane sensitivity, with Research and Motored octane numbers very nearly equal, while other classes of fuels are characterized by significantly different Motor and Research octane numbers. Leppard's work indicated that the higher temperatures, lower pressures, and shorter residence times encountered under the Motor octane test procedures would accentuate NTC behavior of alkane fuels, leading to what he termed "super-rated Motor octane quality" for paraffin fuels. As a result of NTC behavior of paraffinic fuels, under Motored octane test procedures, ignition is delayed until higher compression ratios. The corresponding ignition of aromatic and olefinic fuels is not retarded by NTC behavior to any significant degree, leading to apparently poorer octane quality under Motor conditions. As pointed out by Leppard, it is actually more appropriate to regard aromatic and olefin fuels as representing "normal" behavior, with paraffins representing unusual trends due to the influence of the NTC for these fuels. The present study demonstrates that NTC behavior is observed for these paraffinic fuels under Research octane conditions as well.

For the most part, the NTC features predicted by the model calculations were not seen in the experiments. There are many reasons why this could be expected. The 
species measurements were averaged over hundreds of cycles so that most oscillatory, cycle-to-cycle behavior would be smoothed out. In addition, the model assumption of homogeneous reaction in the engine chamber, combined with a distributed heat loss rate, is only approximately valid. Spatial temperature variations exist in the experiments due to heat transfer to the engine chamber walls. Under most conditions, these variations do not have much influence on the overall system behavior, but under conditions close to the NTC region, areas in the chamber with different temperatures will demonstrate differing responses to temperature increases.

The differences between experimental and computed results for fuels with significant NTC behavior such as the PRF50 - PRF75 mixtures in Fig. 3 can perhaps best be understood by realizing that the computations represent an idealized description of the combustion chamber. Under NTC conditions, the overall rate of reaction declines and the fuel/air mixture becomes more resistant to ignition than at lower compression ratios and gas temperatures and requires a larger $C R$ to achieve autoignition. However, in the real engine, because of heat transfer and other non-ideal phenomena, not all of the reactive mixture in the combustion chamber follows this same reaction path and is therefore actually more reactive than the majority of the reactive mixture. Since ignition in the engine requires only a small portion of the reactive mixture to ignite, the most reactive portion that initiates ignition will not be that portion that is being described by the kinetic model. The observed engine performance will therefore require a significantly lower compression ratio to achieve autoignition than is predicted by the idealized kinetic model. These trends produce the results in Fig. 3 in which the model predictions for the PRF50 - PRF75 mixtures indicate more ignition resistance than observed experimentally. This type of behavior represents a limit to the applicability of purely kinetic models to describe practical engine combustion. 


\section{Chemical Species Concentrations}

There is a great deal of kinetic information in the model calculations. It is convenient to use species concentrations evaluated at the highest compression ratio for which autoignition was not observed, where the greatest fuel consumption would be expected. This comparison is provided in Table II. For the most part, the agreement between computed and experimental species concentrations is good, especially when it is considered that these are time-integrated quantities that cover production and consumption of these species over a wide range of temperature and time. The total fractions of large olefins, cyclic ethers, oxygenated species including aldehydes and ketones, all are excellent agreement with observations, and the relative distributions of different isomeric forms of these intermediates are also well reproduced by the model.

The dominant chemical species observed in the exhaust are those intermediate species common to virtually all hydrocarbon partial oxidation, including $\mathrm{CO}$, formaldehyde, ethene and isobutene. The oxygenated species include some which also are common to all hydrocarbons such as formaldehyde, acetone, acetaldehyde and acrolein. However, the cyclic ethers and larger olefins are very particular to the composition of the primary fuel, as the results in Table II indicate.

In particular, when 2-methyl pentane is the fuel, the dominant cyclic ethers produced are the 5- and 4-membered ring structures that are the obvious products of isomerization reactions of the hexylperoxy radicals formed from the fuel. The same is true for iso-octane, but the specific structures are those which are particular to isooctane evolution. The relatively higher concentrations of the tetrahydrofurans are evident for both fuels, which can be related kinetically to details in the decomposition paths of $\mathrm{QOOH}$ radicals [10]. Similar behavior is seen in Table II for the larger olefins being produced; when 2-methyl pentane is the fuel, $C_{5}$ olefins are produced, while $C_{7}$ and $\mathrm{C}_{8}$ olefins are produced in iso-octane combustion. Finally, the generally good agreement between computed final concentrations and measured concentrations in the 
exhaust indicate that the kinetic model is reliably reproducing the conditions and kinetic evolution in the motored engine. Continuing mechanism refinements are needed to improve the agreement, but these results and related recent studies [11] respresent the first direct comparison of species-specific engine results with kinetic modeling predictions.

\section{SUMMARY}

Autoignition of a variety of hydrocarbon fuels and fuel mixtures has been studied experimentally using motored engine techniques and computationally using a detailed chemical kinetics model. Relative ordering of the critical compression ratios for autoignition of these fuels, and the major intermediate chemical species produced, are all well reproduced by the kinetic model. In addition, negative temperature coefficient phenomena were observed for several of the fuels and fuel mixtures, and this behavior has been related to the more general problem of fuel octane sensitivity. The ability of the kinetic model to provide accurate intermediate chemical species concentrations, even for complex species such as the cyclic ethers and other oxygenates, provides a demanding test of the chemical model not possible anywhere in the past, lending confidence in the validity of the model description of the autoignition chemistry of these hydrocarbon fuels under conditions relevant to engine processes.

\section{ACKNOWLEDGMENTS}

The authors are pleased to acknowledge the contributions of Professor Joseph Bozzelli and Dr. Nick Marinov for their insights and suggestions in this work. This work was supported in part by the U. S. Department of Energy, Office of Transportation Technologies and the Office of Basic Energy Sciences, Chemical Sciences Branch, and carried out under the auspices of the U.S. Department of Energy by the Lawrence Livermore National Laboratory under contract W-7405-ENG-48. 


\section{REFERENCES}

1. Lovell, W. G., Ind. Eng. Chem. 40, 2388 (1948).

2. Vermeersch, M. L., Held, T. J., Stein, Y. S., and Dryer, F. L., SAE Trans. 100, 645 (1991).

3. Cernansky, N. P., Green, R. M., Pitz, W. J., and Westbrook, C. K., Combust. Sci. Technol. 50, 3 (1986).

4. Lignola, P. G., DiMaio, F. P., Marzocchella, A., Mercogliano, R., and Reverchon, E., Twenty-Second Symposium (International) on Combustion, p. 1625, The Combustion Institute, Pittsburgh, 1989.

5. Chakir, A., Bellimam, M., Boettner, J. C., and Cathonnet, M., Int. J. Chem. Kinet. 24, 385 (1992).

6. Cavaliere, A., Ciajolo, A., D'Anna, A., Mercogliano, R., and Ragucci, R., Combust. Flame 93, 279 (1993).

7. Dagaut, P., Reullon, M., and Cathonnet, M., Combust. Sci. Tech. 95, 233 (1994).

8. Minetti, R., Carlier, M. Rivaucour, M. Therssen, E., and Sochet, L. R., Combust. Flame 102, 298 (1995).

9. Griffiths, J. F., Hughes, K. J., Schreiber, M. and Poppe, C., Combust. Flame 99, 533 (1994).

10. Westbrook, C. K., Pitz, W. J., and Leppard, W. R., SAE paper SAE-912314 (1991).

11. Curran, H. J., Gaffuri, P., Pitz, W. J., Westbrook, C. K., and Leppard, W. R., SAE Paper SAE-952406 (1995).

12. Westbrook, C. K., Warnatz, J., and Pitz, W. J., Twenty-Second Symposium (International) on Combustion, p. 893, The Combustion Institute, Pittsburgh, 1988.

13. Chevalier, C., Pitz, W. J., Warnatz, J., Westbrook, C. K., and Melenk, H., TwentyFourth Symposium (International) on Combustion, p. 93, The Combustion Institute, Pittsburgh, 1992.

14. Leppard, W. R., SAE paper SAE-892081 (1989).

15. Leppard, W. R., SAE paper SAE-902137 (1990).

16. Leppard, W. R., SAE paper SAE-922325 (1992). 
17. Lipari, F., and Swarin, S. J., J. Chromatog. 247, 297 (1982).

18. Perry, K. L., J. Chrom. Sci. 28, 624 (1990).

19. Lund, C. M., "HCT - A General Computer Program for Calculating TimeDependent Phenomena Involving One-Dimensional Hydrodynamics, Transport, and Detailed Chemical Kinetics," Lawrence Livermore National Laboratory report UCRL-52504 (1978).

20. Heywood, J. B., "Internal Combustion Engine Fundamentals," McGraw-Hill Publishing Co., New York, 1988.

21. Green, R. M., Cernansky, N. P., Pitz, W. J., and Westbrook, C. K., SAE paper SAE-872108 (1987).

22. Benson, S. W., "Thermochemical Kinetics," Wiley, New York, 1976.

23. Lay, T., and Bozzelli, J.W., Eastern States Meeting of the Combustion Institute, paper no. 100 (1993).

24. Ritter, E. R., and Bozzelli, J. W., Int. J. Chem. Kinet. 23, 767 (1991).

25. Ranzi, E., Gaffuri, P., Faravelli, T., and Dagaut, P., Combust. Flame, in press (1995).

26. Curran, H. J., Gaffuri, P., Pitz, W. J., and Westbrook, C. K., in preparation (1995).

27. Curran, H. J., Pitz, W. J., Westbrook, C. K., Hisham, K., and Walker, R. W., submitted for publication (1996).

28. Cox, R. A., and Cole, J. A., Combust. Flame 60, 109 (1985).

29. Hu, H., and Keck, J. C., SAE Paper 872110 (1987).

30. Morley, C., Combust. Sci. Technol. 55, 115 (1987).

31. Sahetchian, K. A., Rigny, R. and Circan, S., Combust. Flame 85, 511 (1991).

32. Li, H., Prabhu, S. K., Miller, D. L., and Cernansky, N. P., SAE Paper SAE-942062 (1994). 


\section{Table I}

Summary of fuels included in this study, including Research Octane Number (RON), experimentally measured critical compression ratio, and critical compression ratio predicted by the computational model. Pentane isomers not measured experimentally. Values indicated by (6.0) ignited at $C R=6.0$ but are expected to have a critical CR only slightly lower than 6.0 .

$\begin{array}{cccc}\text { Fuel } & \text { RON } & \begin{array}{c}\text { Experimental } \\ \text { Critical CR }\end{array} & \begin{array}{c}\text { Predicted } \\ \text { Critical CR }\end{array} \\ \text { 0 PRF } & 0 & 6.3 & (6.0) \\ \text { n-hexane } & 25 & 6.4 & (6.0) \\ \text { 25 PRF } & 25 & 6.8 & 6.5 \\ \text { 50 PRF } & 50 & 7.3 & 6.5 \\ \text { 60 PRF } & 60 & \mathrm{n} / \mathrm{a} & 10.0 \\ \text { n-pentane } & 62 & \mathrm{n} / \mathrm{a} & (6.0) \\ \text { 70 PRF } & 70 & \mathrm{n} / \mathrm{a} & 11.25 \\ \text { 2-methyl pentane } & 73 & 8.1 & 8.7 \\ \text { 3-methyl pentane } & 75 & 8.4 & 8.7 \\ \text { 75 PRF } & 75 & 9.1 & 11.5 \\ \text { 2,2-dimethyl propane } & 85 & \mathrm{n} / \mathrm{a} & 9.0 \\ \text { 2-methyl butane } & 92 & 12.0 & 17.7 \\ \text { 85 PRF } & 85 & 10.5 & 12.25 \\ \text { 90 PRF } & 90 & 12.0 & 14.75 \\ \text { 2,2-dimethyl butane } & 92 & 11.5 & 10.5 \\ \text { 95 PRF } & 95 & 13.7 & 16.25 \\ \text { 100 PRF } & 100 & 16.7 & 17.3 \\ \text { 2,3-dimethyl butane } & 104 & 19.0 & 19.5\end{array}$




\section{Table II}

Experimentally measured and computed exhaust species concentrations for combustion of 2-methyl pentane and iso-octane mixtures under motored conditions close to autoignition. For 2-methyl pentane, experiments are at $C R=8.0$, model results at $C R=8.75$, for iso-octane, experiments are at $C R=10.5$, model results at $C R=10.0$.

Species

Carbon monoxide

Formaldehyde

Ethene

Acetaldehyde

Propionaldehyde

Acetone

Acrolein

Isobutene

2-methyl pentane

2-methyl-1-pentene

2-methyl-2-pentene

2,2,4-trimethyloxetane

2,2-dimethyltetrahydrofuran

2,4-dimethyltetrahydrofuran

Carbon monoxide

Formaldehyde

Acetone

Propene

Methacrolein

Isobutene

4,4-dimethyl-2-pentene

2,4-dimethyl-2-pentene

2,4,4-trimethyl-1-pentene

2,4,4-trimethyl-2-pentene

2,2,4,4-tetramethyl tetrahydrofuran

2-isopropyl-3,3-dimethyloxetan

\section{Experimental Model \\ Concentration Concentration \\ (ppm) \\ (ppm)}

2-methyl pentane (600 rpm)

$\begin{array}{rr}6390 & 9760 \\ 2107 & 4800 \\ 579 & 2300 \\ 1457 & 686 \\ 479 & 744 \\ 138 & 2400 \\ 159 & 169 \\ 534 & 453 \\ 12505 & 8860 \\ 356 & 827 \\ 215 & 872 \\ 243 & 244 \\ 323 & 498 \\ 248 & 414 \\ & \\ \text { iso-octane (500 rpm) }\end{array}$

2310

1170

3550

818

2300

323

1270

637

235

1694

1330

252

60

168

232

152

480

792

1011

425

1360 


\section{Table III}

Computed mole fractions of selected species during successive model engine cycles. The first series describes results for CR less than the critical value, the second series shows ignition on the seventh engine cycle, the third series shows oscillatory behavior.

$\begin{array}{cccccc}\text { Fuel } & \begin{array}{c}\text { Engine } \\ \text { cycle }\end{array} & \mathrm{iC}_{8} \mathrm{H}_{18} & \mathrm{nC}_{7} \mathrm{H}_{16} & \mathrm{CH}_{2} \mathrm{O} & \mathrm{CO}_{2} \\ \text { 95\% iso-octane } & 1 & 1.56 \mathrm{e}-2 & 8.17 \mathrm{e}-4 & 1.76 \mathrm{e}-5 & 4.32 \mathrm{e}-7 \\ 5 \% \text { n-heptane } & 2 & 6.95 \mathrm{e}-3 & 2.90 \mathrm{e}-4 & 3.12 \mathrm{e}-3 & 1.79 \mathrm{e}-4 \\ \text { (95 PRF) } & 3 & 8.83 \mathrm{e}-3 & 3.97 \mathrm{e}-4 & 2.49 \mathrm{e}-3 & 1.38 \mathrm{e}-4 \\ & 4 & 8.60 \mathrm{e}-3 & 3.83 \mathrm{e}-4 & 2.57 \mathrm{e}-3 & 1.40 \mathrm{e}-4 \\ \mathrm{CR}=12.0 & 5 & 8.64 \mathrm{e}-3 & 3.85 \mathrm{e}-4 & 2.55 \mathrm{e}-3 & 1.39 \mathrm{e}-4 \\ & 6 & 8.64 \mathrm{e}-3 & 3.85 \mathrm{e}-4 & 2.55 \mathrm{e}-3 & 1.39 \mathrm{e}-4\end{array}$

\begin{tabular}{|c|c|c|c|c|c|}
\hline Fuel & $\begin{array}{l}\text { Engine } \\
\text { cycle }\end{array}$ & $\mathrm{nC}_{6} \mathrm{H}_{14}$ & $\mathrm{CO}$ & $\mathrm{CH}_{2} \mathrm{O}$ & $\mathrm{CO}_{2}$ \\
\hline \multirow[t]{4}{*}{ n-hexane } & 1 & $2.16 e-2$ & $3.54 e-11$ & $1.36 \mathrm{e}-11$ & $1.00 e-13$ \\
\hline & 2 & $2.16 e-2$ & $6.25 e-10$ & $2.37 e-10$ & $2.80 \mathrm{e}-12$ \\
\hline & 3 & $2.16 \mathrm{e}-2$ & $8.67 e-9$ & $3.34 \mathrm{e}-9$ & $5.09 e-11$ \\
\hline & 4 & $2.16 e-2$ & $1.18 \mathrm{e}-7$ & $5.26 \mathrm{e}-8$ & $1.93 e-9$ \\
\hline \multirow[t]{2}{*}{$C R=5.75$} & 5 & $2.15 e-2$ & $1.71 e-6$ & $1.23 e-6$ & $6.52 \mathrm{e}-8$ \\
\hline & $\begin{array}{l}6 \\
7\end{array}$ & $\begin{array}{l}1.78 \mathrm{e}-2 \\
\text { autoignition }\end{array}$ & $1.86 \mathrm{e}-4$ & $1.72 e-4$ & $8.32 e-6$ \\
\hline \multirow[t]{2}{*}{ Fuel } & Engine & $\mathrm{iC}_{8} \mathrm{H}_{18}$ & $\mathrm{nC}_{7} \mathrm{H}_{16}$ & $\mathrm{CH}_{2} \mathrm{O}$ & $\mathrm{CO}_{2}$ \\
\hline & cycle & & & & \\
\hline $75 \%$ iso-octane & 1 & $1.25 e-2$ & $4.15 e-3$ & $4.35 e-8$ & $9.88 \mathrm{e}-10$ \\
\hline $25 \%$ n-heptane & 2 & $1.26 \mathrm{e}-2$ & $4.19 e-3$ & $6.16 e-6$ & $1.70 \mathrm{e}-7$ \\
\hline \multirow[t]{2}{*}{ (75 PRF) } & 3 & $5.08 \mathrm{e}-3$ & $1.29 e-3$ & $4.51 \mathrm{e}-3$ & $2.70 e-4$ \\
\hline & 4 & $1.12 e-2$ & $3.65 e-3$ & $8.77 e-4$ & $5.43 e-5$ \\
\hline \multirow[t]{5}{*}{$C R=7.0$} & 5 & $5.02 e-3$ & $1.27 e-3$ & $4.71 e-3$ & $3.22 \mathrm{e}-4$ \\
\hline & 6 & $1.12 e-2$ & $3.65 e-3$ & $9.15 e-4$ & $6.44 e-5$ \\
\hline & 7 & $5.02 e-3$ & $1.27 e-3$ & $4.71 e-3$ & $3.26 e-4$ \\
\hline & 8 & $1.12 \mathrm{e}-2$ & $3.65 e-3$ & $9.15 e-4$ & $6.52 e-5$ \\
\hline & 9 & $5.02 e-3$ & $1.27 e-3$ & $4.71 \mathrm{e}-3$ & $3.26 e-4$ \\
\hline
\end{tabular}




\section{FIGURE CAPTIONS}

1. CO exhaust concentrations as functions of compression ratio for the five isomeric hexanes. For compression ratios slightly greater than the last point plotted for each fuel, autoignition was observed. The upper curves show computed model results, the lower curves show experimental results.

2. CO exhaust concentrations as functions of compression ratio for selected PRF mixtures. For compression ratios slightly greater than the last point plotted for each fuel, autoignition was observed. The upper curves show computed model results, the lower curves show experimental results.

3. Correlations between Research Octane Number (RON) and critical compression ratio. The lines connect experimentally determined values, with the solid line describing the PRF mixtures and the dashed line describing the hexane isomers. The filled symbols indicate experimental critical compression ratios, the open symbols indicate computed values. 

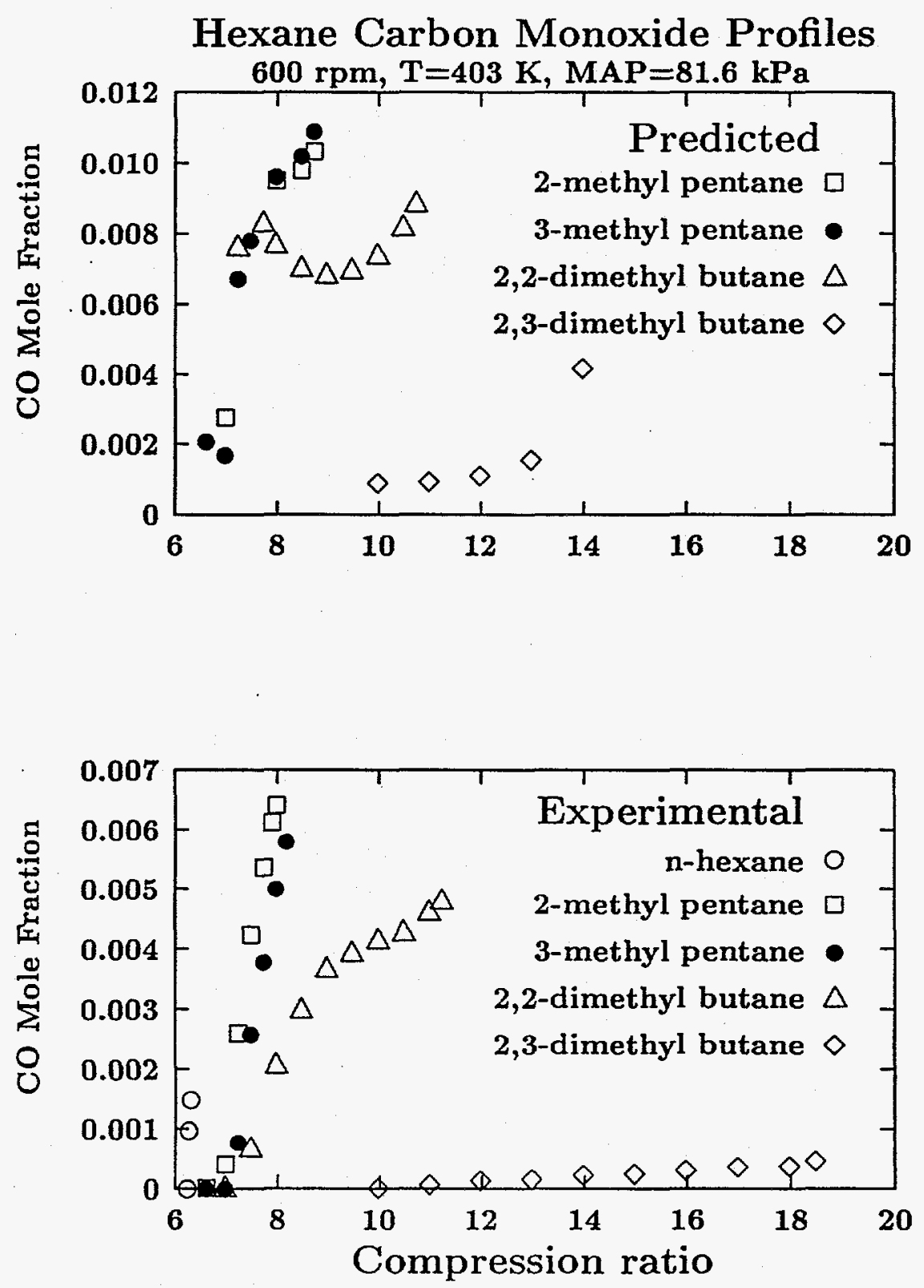

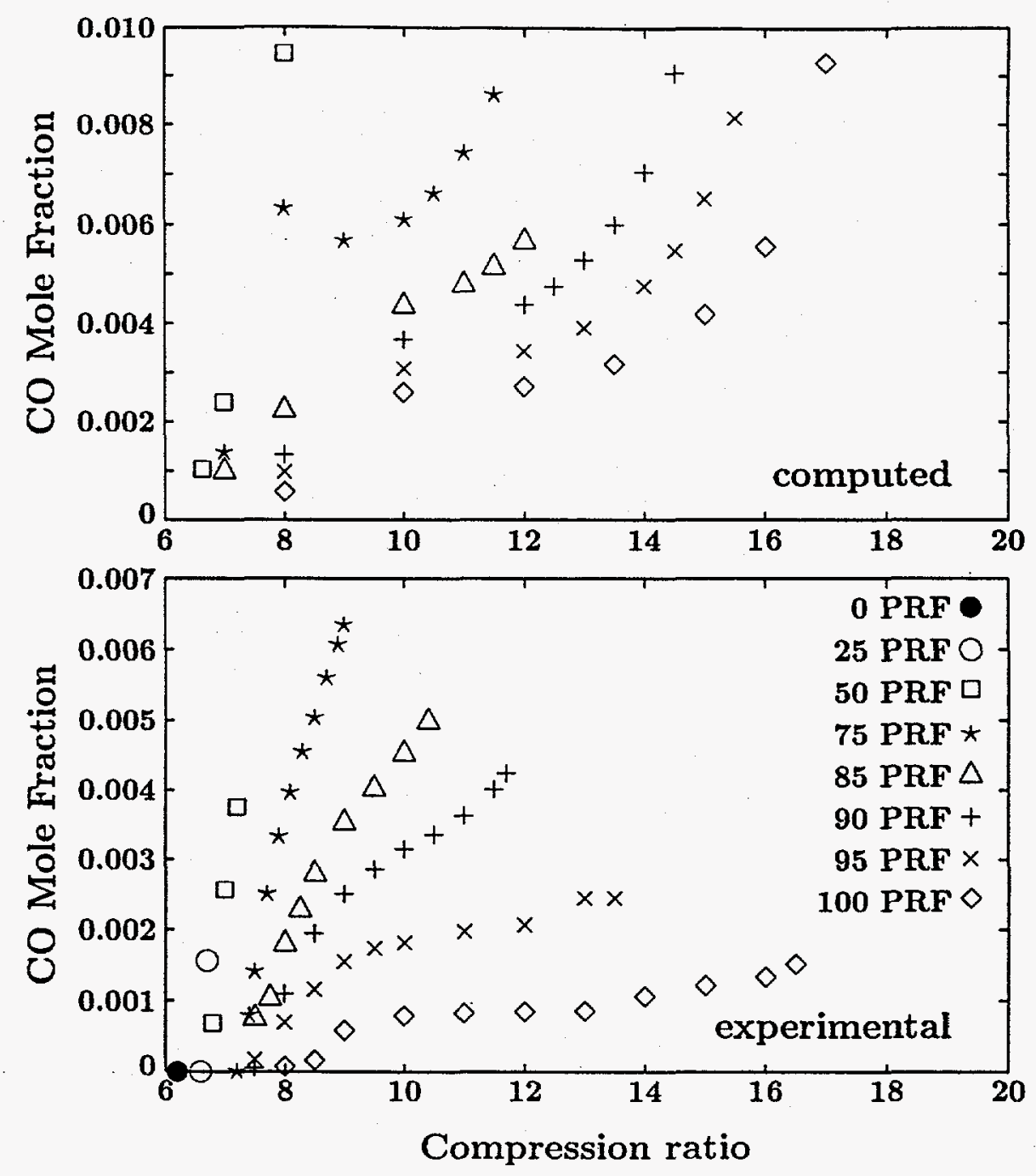


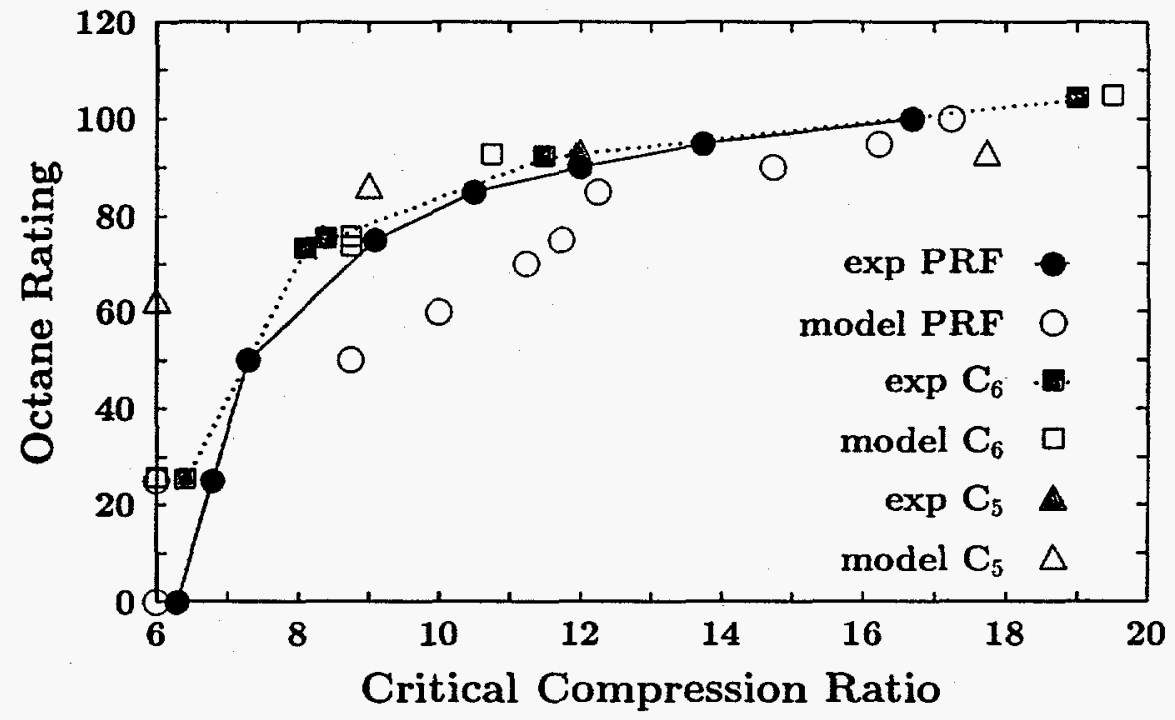





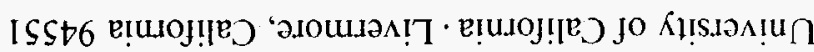

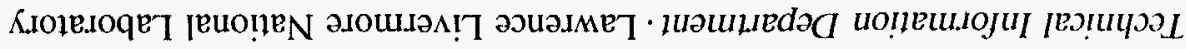

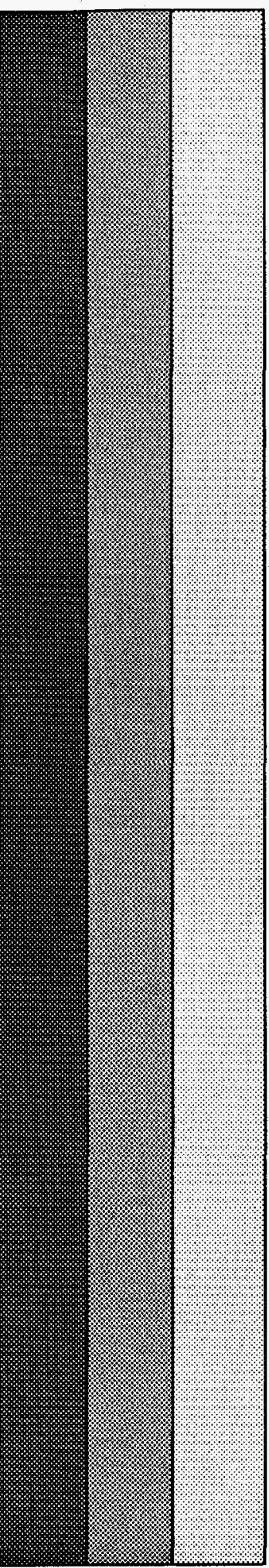

$\cdots \quad$, 